\title{
Inhibiting cell viability and motility by Layer-by-Layer assembly and biomineralization
}

Yan Wei*, Hao Xu, Shuangmeng Xu, Hui Su, Lichuang Zhang, Ruize Sun, Di Huang*, Liqin Zhao, Kaiqun Wang, Yinchun Hu and Xiaojie Lian

Department of Biomedical Engineering, Research Center for Nano-biomaterials \& Regenerative Medicine, College of Biomedical Engineering, Taiyuan University of Technology, Taiyuan 030024, PR China

*Corresponding authors. Tel: +86-351-6014477; Fax: +86-351-6011816.

E-mail address: weiyan@tyut.edu.cn (Yan Wei); huangjw2067@163.com (Di Huang) 


\section{Supporting Information}

Table S1. Physiochemical properties of polymers used in this study

\begin{tabular}{ccc}
\hline polymer $^{\mathrm{a}}$ & species & molecular weight $(\mathrm{kDa})$ \\
\hline PDDA & synthetic polymer & 100 \\
PSS & synthetic polymer & 70 \\
$\varepsilon-$ Lys & naturally occurring polymer & 5.0 \\
PDA & synthetic polymer & 0.200 \\
\hline
\end{tabular}

${ }^{a}$ PDDA, poly(diallyldimethylammonium chloride); PSS, poly(styrenesulfate sodium salt); $\varepsilon$-Lys, $\varepsilon$-poly(lysine hydrochloride); PDA, dopamine hydrochloride

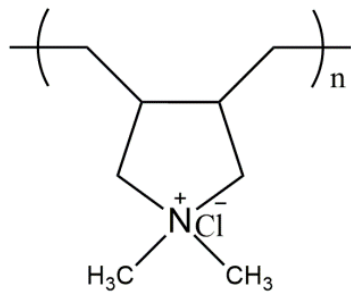

PDDA<smiles>CC(C)(C)CC(c1ccc(S(=O)(=O)[O-])cc1)C(C)(C)C</smiles>

PSS<smiles>CC(C)(C)NCCCCC(N)C(=O)NC(C)(C)C</smiles>

Lys<smiles>CCCCOC(=O)OC(C)(C)C</smiles>

Figure S1. Chemical structures of the cationic and anionic polymers used in this study 

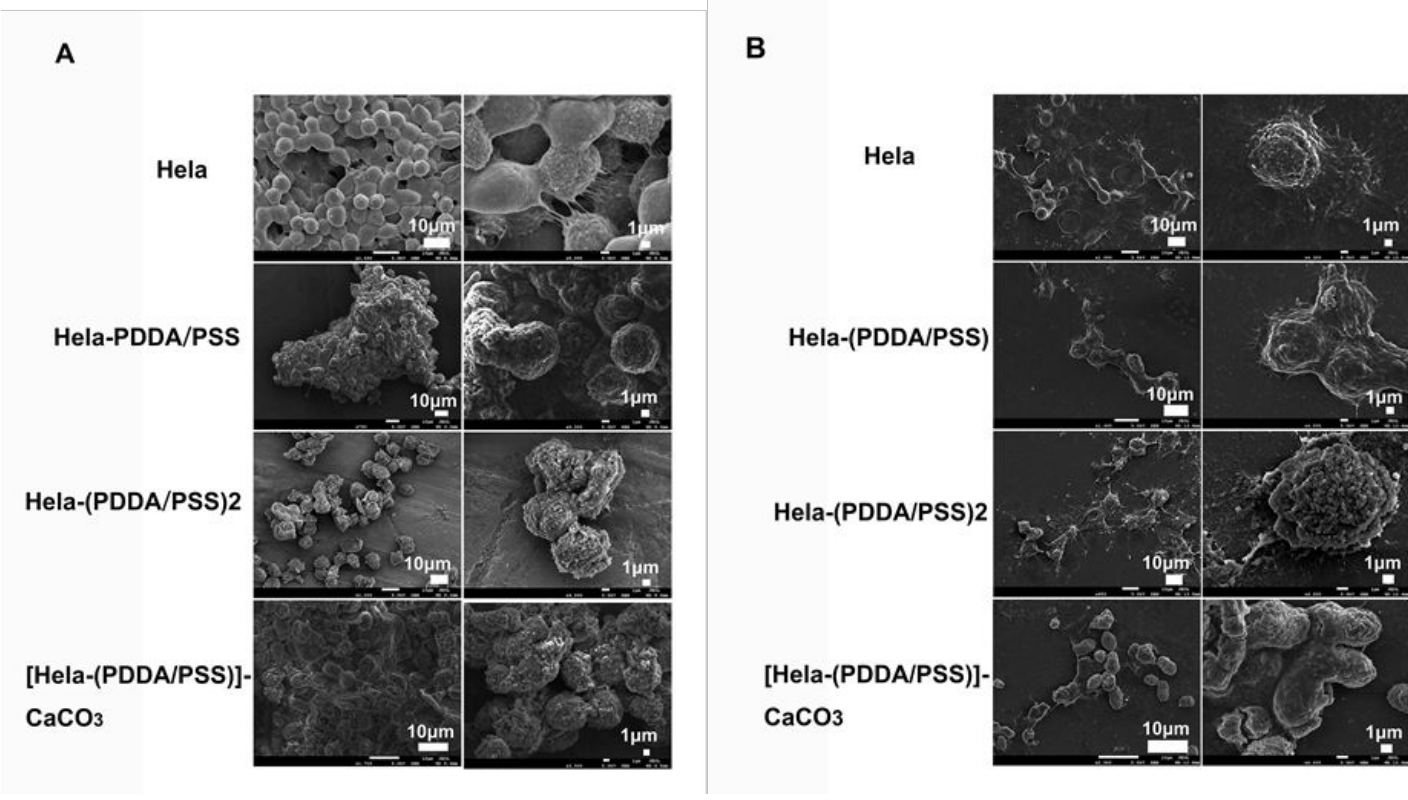

Figure S2. SEM images of the HeLa cells coating with PDDA/PSS films after $24 \mathrm{~h}$ of incubation. A)Cells coating with the films before adhesive on the glass sheet; B) cells coating with the films after adherent growth on the glass sheet; the left panel represents SEM images with low multiples, and the right panel represents the higher multiple. 




\section{C}


Figure S3. SEM images of the HeLa cells coating with PDDA/PSS films and calcium phosphate shells after $24 \mathrm{~h}$ of incubation. A) cells coating with the films before adhesive on the glass sheet; B) cells coating with the films after adherent growth on the glass sheet; C) The EDX mapping of component elements of the mineral shell around the cell surface. 


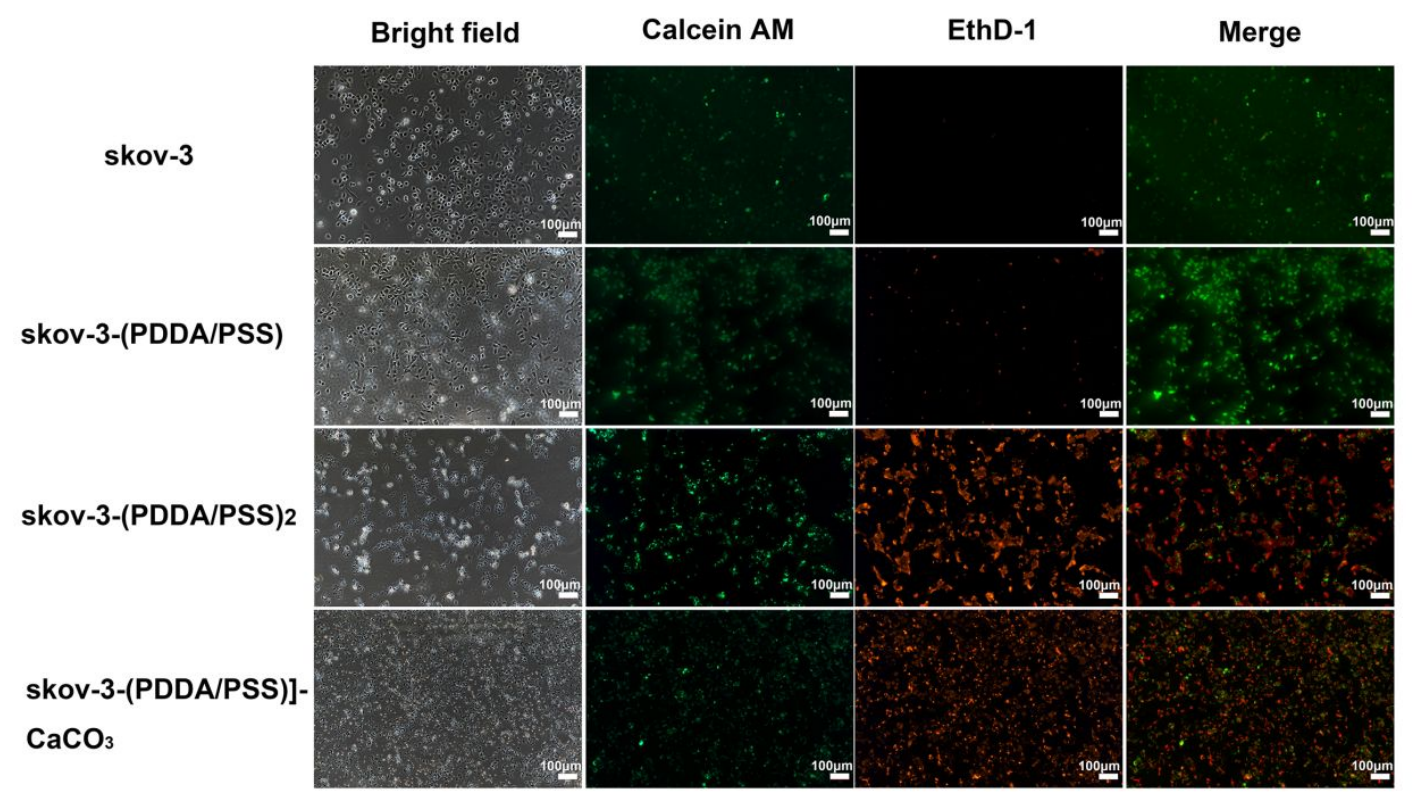

Figure S4. Fluorescence microscopic images of polyelectrolytes films (PDDA/PSS) or mineral shells prepared on the SKOV-3 cells after $24 \mathrm{~h}$ incubation. The cells were stained with calcein-AM/EthD-1 kit. Dead or late apoptotic cells appear red while the living cells appear green in the fluorescence microscopy. 


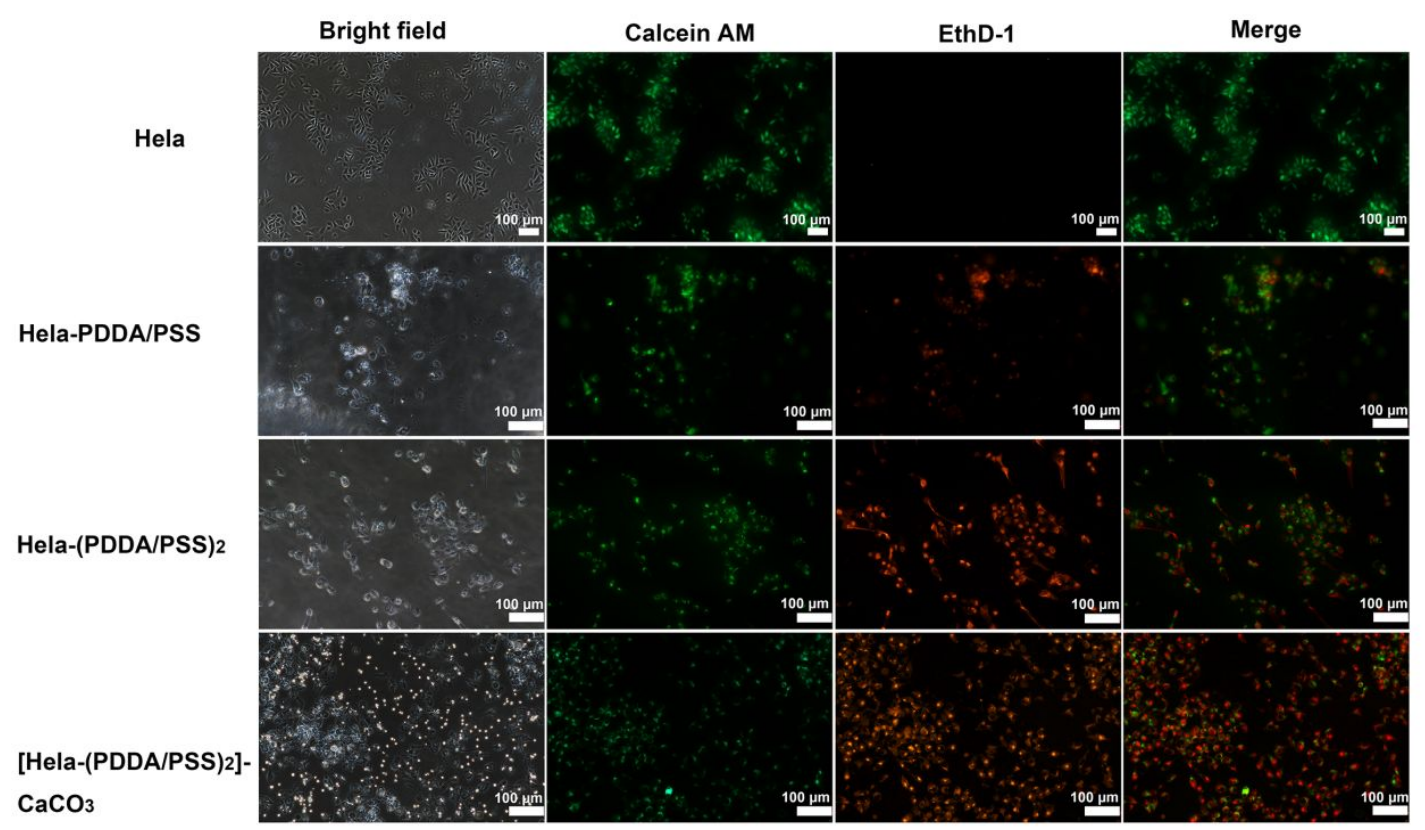

Figure S5. Fluorescence microscopic images of polyelectrolytes films (PDDA/PSS) or mineral shells prepared on the HeLa cells after $24 \mathrm{~h}$ incubation. The cells were stained with calcein-AM/EthD-1 kit. Dead or late apoptotic cells appear red while the living cells appear green in the fluorescence microscopy. 
A



B

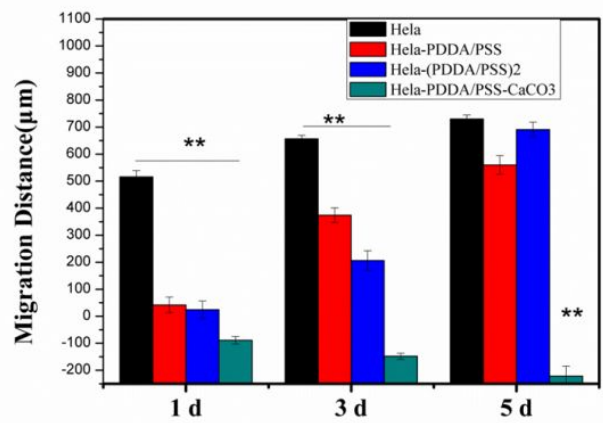

C



D

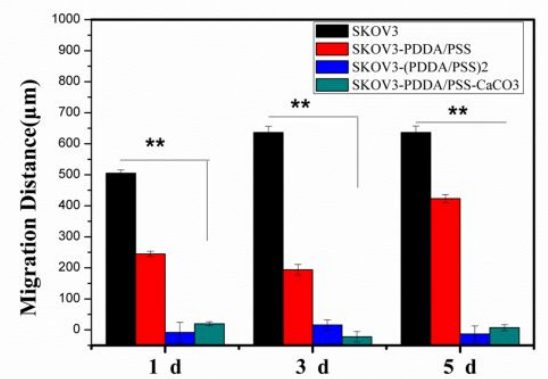

Figure S6. Effects of PDDA/PSS films or mineral shells on the migration of cell lines by the scratch wound healing assay. (A) Migration of HeLa cells coating with PDDA/PSS and $\mathrm{CaCO}_{3}$ at $0,1,3$ and $5 \mathrm{~d}$ (white scale bar=100 $\mu \mathrm{m}$ ). (B) Migration distance of HeLa cells coating with PDDA/PSS and $\mathrm{CaCO}_{3}$ at $0,1,3$ and 5 d. (C) Migration of SKOV-3 cells coating with PDDA/PSS films and $\mathrm{CaCO}_{3}$ at $0,1,3$ and $5 \mathrm{~d}$ (white scale bar=100 $\mu \mathrm{m}$ ). (D) Migration distance of SKOV-3 cells coating with PDDA/PSS and $\mathrm{CaCO}_{3}$ at $0,1,3$ and $5 \mathrm{~d}$. (**) denote a statistically significant difference between the samples calculated by a two sample $t$ test. 
A



C

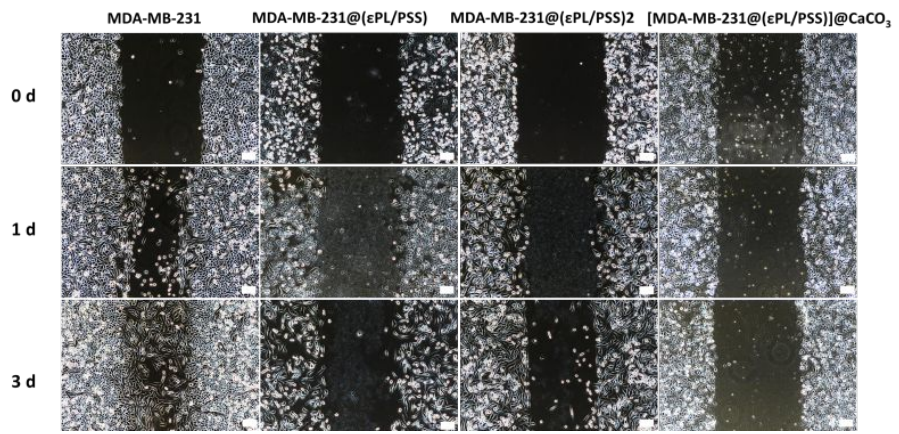



D

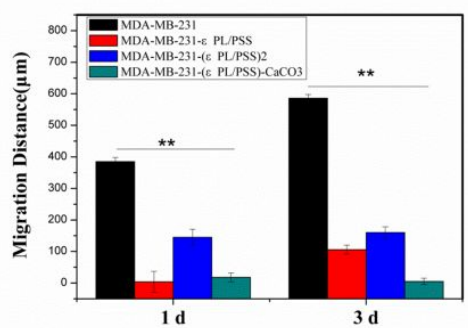

Figure S7. Effects of various polyelectrolyte films or mineral shells on the migration of MDA-MB-231 cell lines by the scratch wound healing assay. (A) Migration of MDA-MB-231 cells coating with PDA/PSS and $\mathrm{CaCO}_{3}$ at $0,1,3 \mathrm{~d}$ (white scale bar $=100 \mu \mathrm{m}$ ). (B) Migration distance of MDA-MB-231 cells coating with $\varepsilon \mathrm{PL} / \mathrm{PSS}$ and $\mathrm{CaCO}_{3}$ at $0,1,3 \mathrm{~d}$. (C) Migration of MDA-MB-231 cells coating with $\varepsilon$ PL/PSS films and $\mathrm{CaCO} 3$ at $0,1,3 \mathrm{~d}$ (white scale bar $=100$ $\mu \mathrm{m})$. (D) Migration distance of MDA-MB-231 cells coating with $\varepsilon \mathrm{PL} / \mathrm{PSS}$ and $\mathrm{CaCO}_{3}$ at $0,1,3 \mathrm{~d}$. $(* *)$ denote a statistically significant difference between the samples calculated by a two sample $\mathrm{t}$ test. 


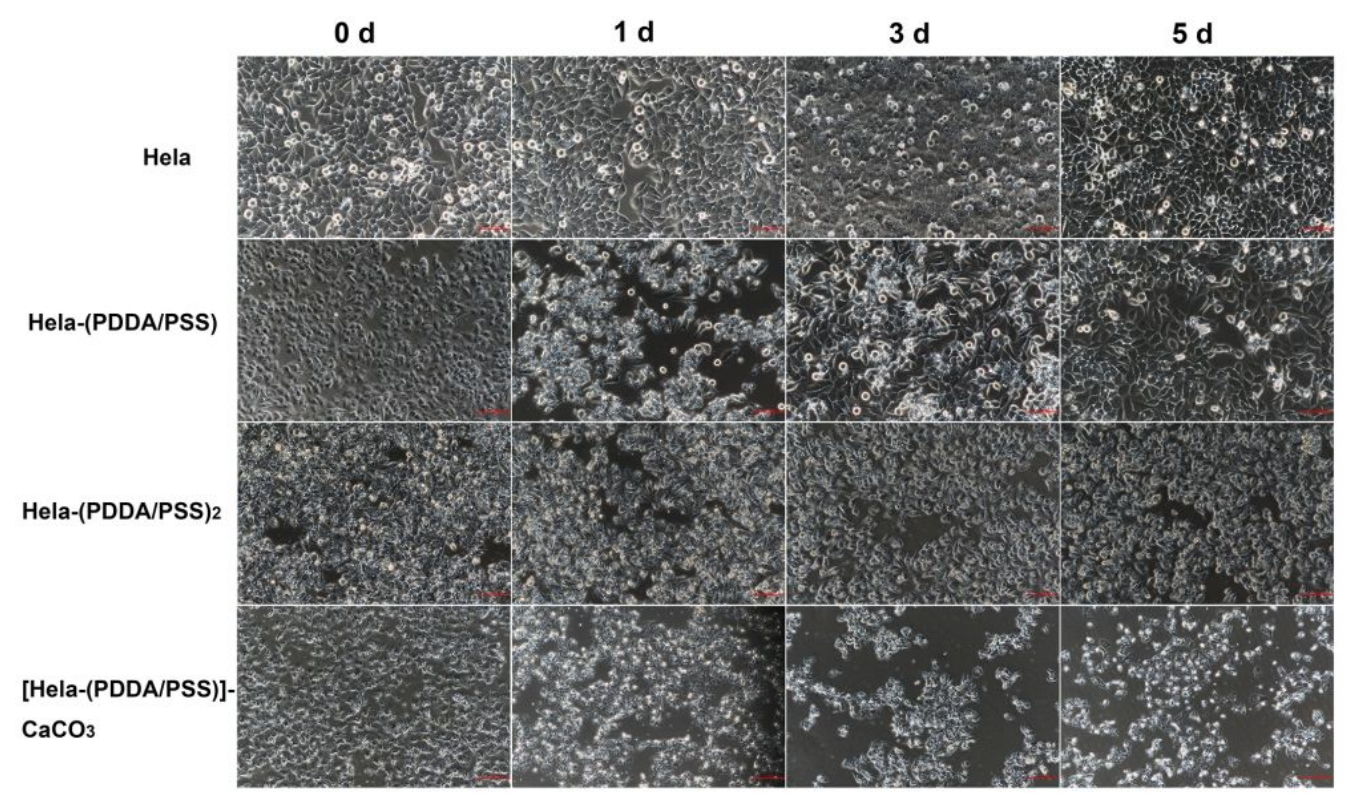

Figure S8. Morphology of HeLa cells before and after coated with PDDA/PSS films and $\mathrm{CaCO}_{3}$ shells for 1,3 , and 5 days at $37^{\circ} \mathrm{C}$.(red scale bar $=100 \mu \mathrm{m}$ ) 


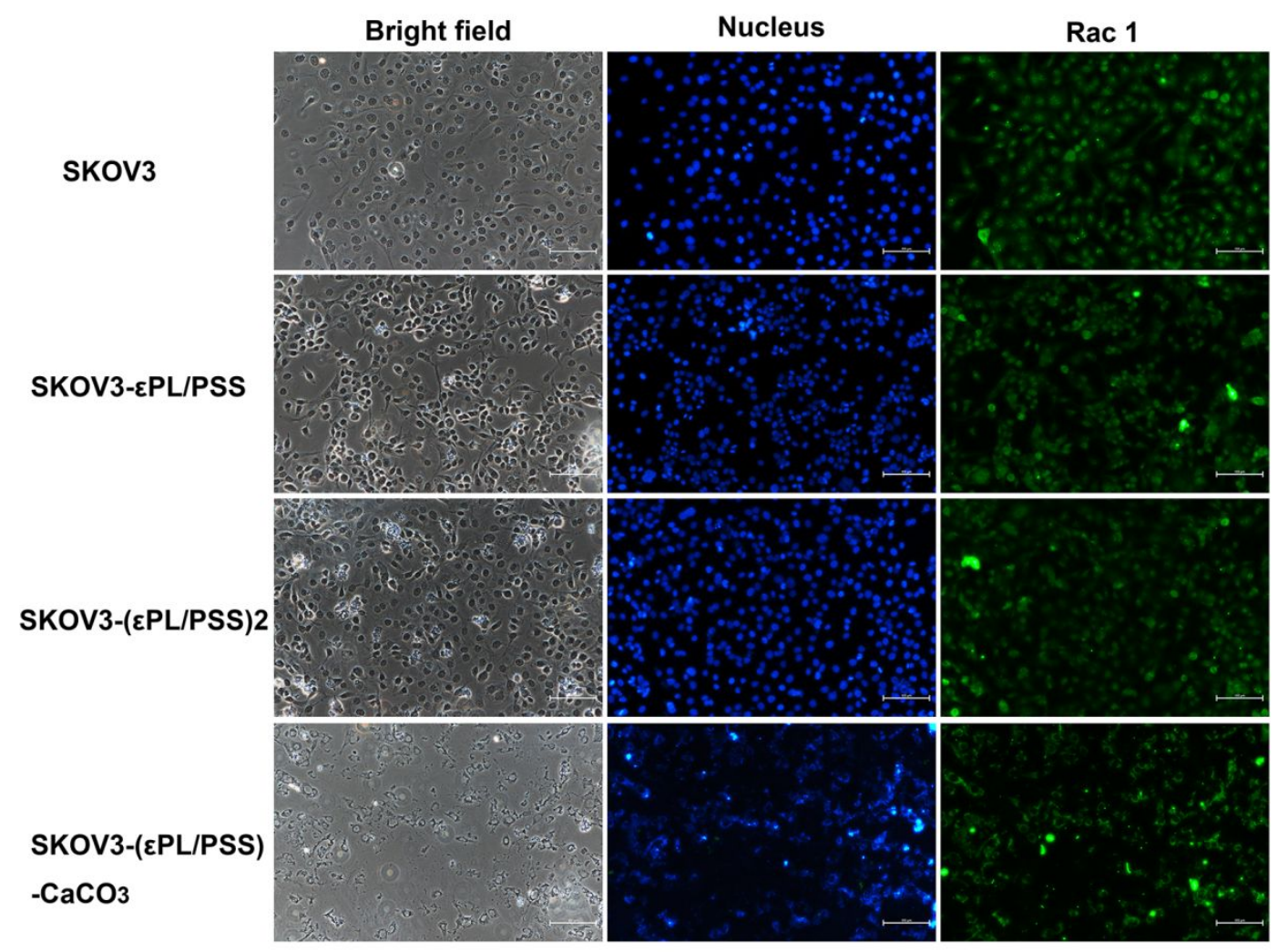

Figure S9. Immunofluorescence analyses of the effects of various polyelectrolytes films or mineral shells on the expression and distribution of Rac 1 after $24 \mathrm{~h}$ co-culture. (White scale bar: $100 \mu \mathrm{m})$ 


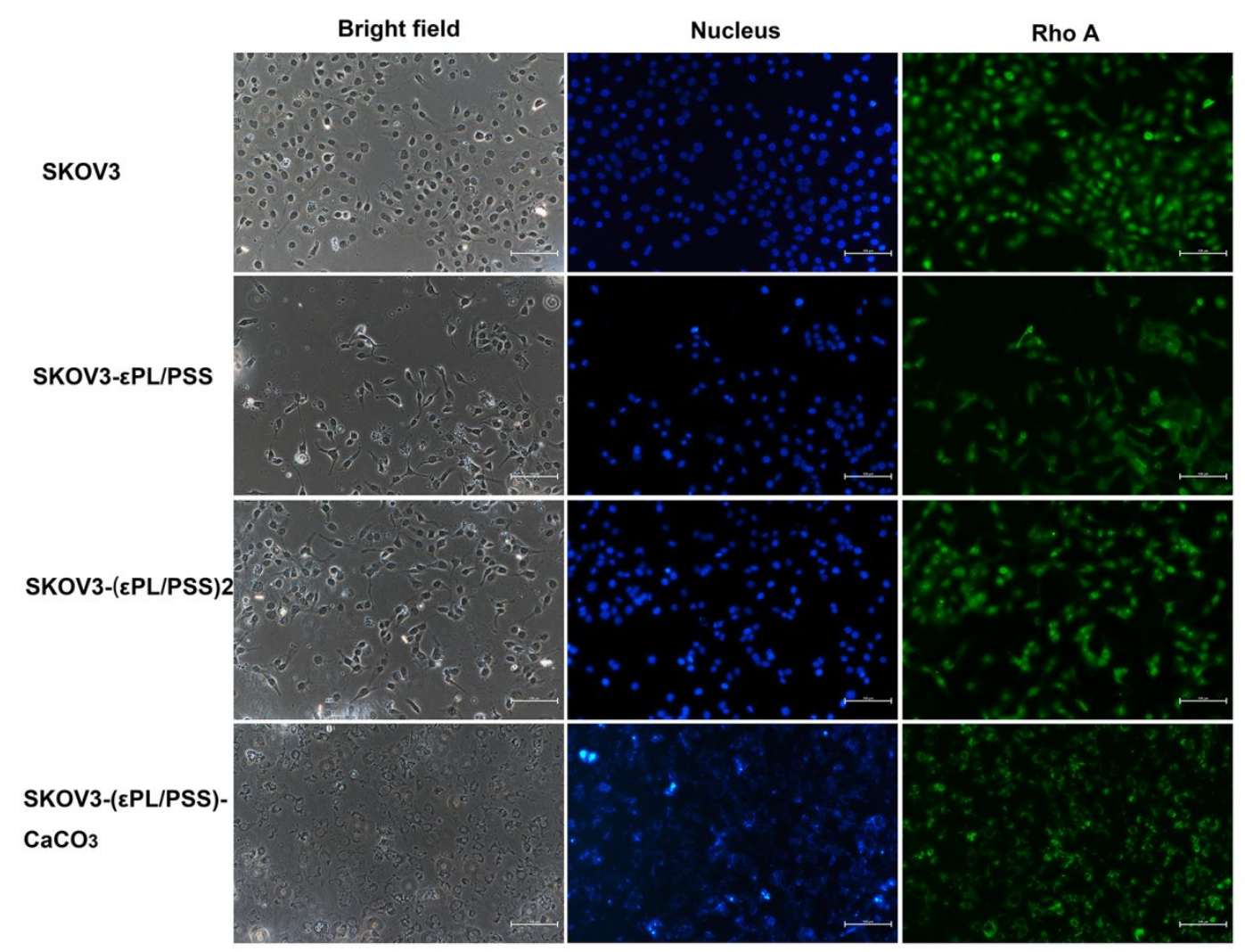

Figure S10. Immunofluorescence analyses of the effects of various polyelectrolytes films or mineral shells on the expression and distribution of Rho A after $24 \mathrm{~h}$ co-culture. (White scale bar: $100 \mu \mathrm{m})$ 


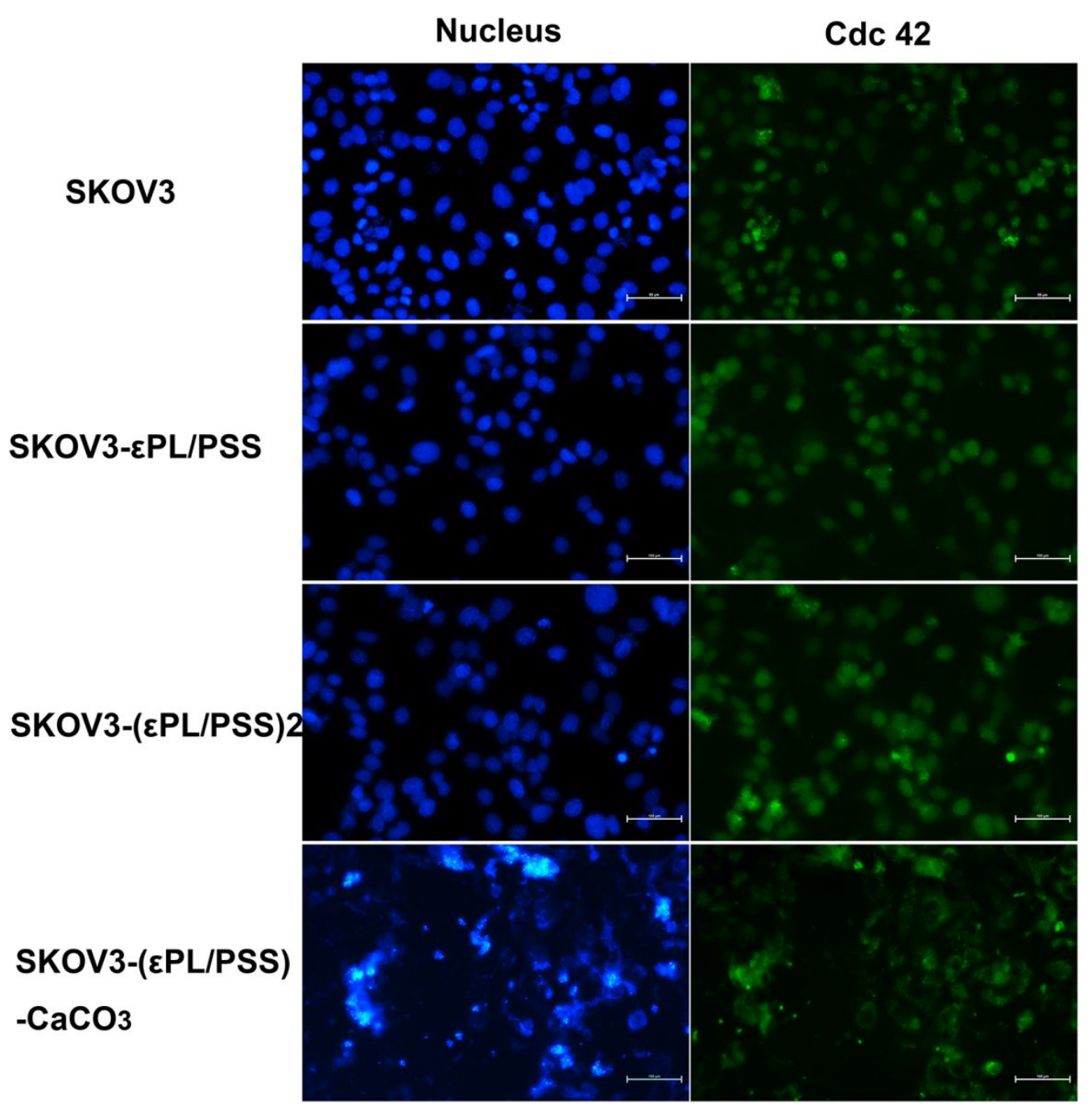

Figure S11. Immunofluorescence analyses of the effects of various polyelectrolytes films or mineral shells on the expression and distribution of Cdc 42 after $24 \mathrm{~h}$ co-culture. (White scale bar: $100 \mu \mathrm{m})$ 




Figure S12. Concentration of MMP-9 of SKOV-3 cells coated with PDA/GE and $\mathrm{CaCO}_{3}$. The asterisks $(*)$ denote a statistically significant difference between the samples calculated by a two sample $t$ test. 


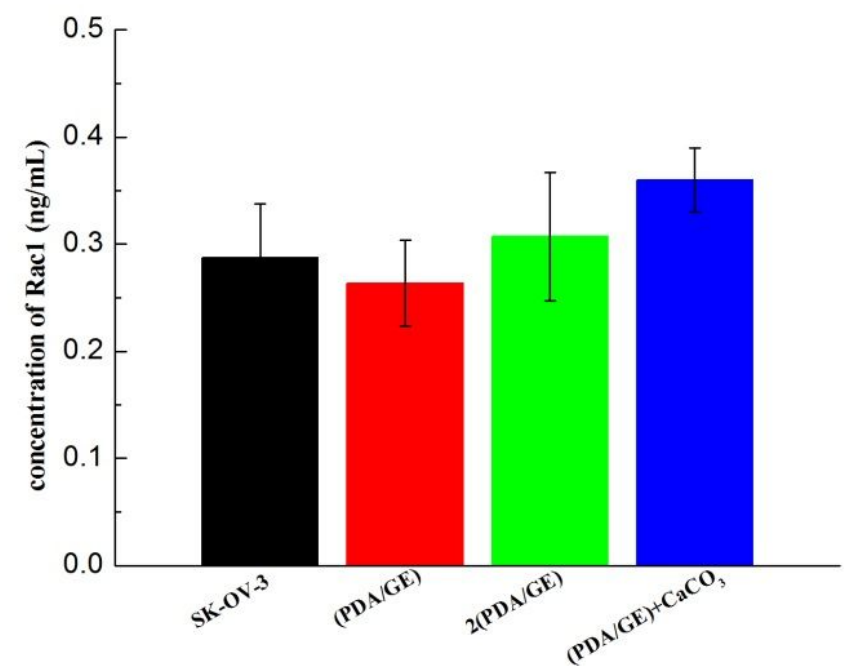

Figure S13.Concentration of Rac1 of SKOV-3 cells coated with PDA/GE and $\mathrm{CaCO}_{3}$. 